\title{
Androgen Deprivation and Thromboembolic Events in Men with Prostate Cancer
}

\author{
Behfar Ehdaie ${ }^{1,2}$, Coral L. Atoria ${ }^{2}$, Amit Gupta ${ }^{1}$, Andrew Feifer ${ }^{1}$, William T. Lowrance ${ }^{1}$, \\ Michael J. Morris ${ }^{3}$, Peter T. Scardino ${ }^{1}$, James A. Eastham ${ }^{1}$, and Elena B. Elkin ${ }^{2}$ \\ ${ }^{1}$ Urology Service, Department of Surgery, Memorial Sloan-Kettering Cancer Center, New York, \\ NY \\ ${ }^{2}$ Health Outcomes Research Group, Department of Epidemiology and Biostatistics, Memorial \\ Sloan-Kettering Cancer Center, New York, NY \\ ${ }^{3}$ Genitourinary Oncology Service, Department of Medicine, Memorial Sloan-Kettering Cancer \\ Center, New York, NY USA
}

\begin{abstract}
Background-Androgen deprivation therapy (ADT) improves prostate cancer outcomes in specific clinical settings, but is associated with adverse effects, including cardiac complications and possibly thromboembolic complications. Our objective was to estimate the impact of ADT on thromboembolic events (TEs) in a population-based cohort.
\end{abstract}

Methods-In the linked Surveillance, Epidemiology and End Results (SEER)-Medicare database, we identified men aged over 65 diagnosed with non-metastatic prostate cancer between 1999 and 2005. Medical or surgical ADT was identified by Medicare claims for gonadotropinreleasing hormone agonists or bilateral orchiectomy at any time following diagnosis. TEs included deep venous thrombosis, pulmonary embolism, and arterial embolism. We estimated ADT's impact on the risk of any TE and on total number of events, controlling for patient and tumor characteristics.

Results-Of 154,611 prostate cancer patients, 58,466 (38\%) received ADT. During a median follow-up of 52 months, 15,950 men had at least one TE, including 8,829 (55\%) who had ADT and $7,121(45 \%)$ with no ADT. ADT was associated with increased risk of a TE (adjusted hazard ratio $1.56,95 \% \mathrm{CI}$ : 1.50 to $1.61, P<0.0001$ ), and duration of ADT was associated with the total number of events $(P<0.0001)$.

Conclusion-In this population-based cohort, ADT was associated with increased risk of a TE, and longer durations of ADT were associated with more TEs. Men with intermediate- and low-risk prostate cancer should be assessed for TE risk factors before starting ADT and counseled regarding the risks and benefits of this therapy.

\section{Keywords}

prostate cancer; deep vein thrombosis; pulmonary embolism; androgen deprivation; arterial embolism

Corresponding author: Behfar Ehdaie, MD Urology Service, Department of Surgery Memorial Sloan-Kettering Cancer Center 1275 York Ave. New York, NY 10065 Phone: 646-735-8141 Fax: 646-735-0011 behdaie79@ gmail.com.

Contributors The study was designed by BE, AG, AF, WTL, PTS, JAE, and EBE. Data were analyzed by BE, CLA and EBE. The report was written by BE, CLA, AG, MJM, PTS, JAE, and EBE with contributions and final approval of all authors.

Conflicts of interest None 


\section{INTRODUCTION}

Prostate cancer is the most common malignancy in men, with more than 200,000 new cases in the United States in 2010. ${ }^{1}$ The majority of patients diagnosed with prostate cancer have localized disease and a favorable prognosis. ${ }^{2}$ Androgen deprivation therapy (ADT), with gonadotropin-releasing hormone $(\mathrm{GnRH})$ agonists or bilateral orchiectomy, is widely used in the treatment of prostate cancer. The use of ADT has increased steadily in the last two decades among men with all stages and grades of tumor, and primary ADT is the second most common treatment for men with localized prostate cancer. ${ }^{3,4}$ Its efficacy is clearly supported in men with metastatic disease. ${ }^{5}$ However, the benefit of ADT is less clear in the non-metastatic setting. Evidence from randomized trials supports the use of ADT in patients with high-risk localized prostate cancer treated with radiation therapy. ${ }^{4}$ The role of ADT in the setting of intermediate- and low-risk prostate cancer, however, is not well defined.

For every prostate cancer patient considering ADT, the potential benefits of treatment must be weighed against the risks. Men taking ADT often experience hormonal side effects such as hot flashes, loss of libido, and erectile dysfunction. ${ }^{6,7}$ ADT is also associated with more serious adverse effects, including skeletal fractures, cardiovascular disease, insulin insensitivity, increased fat mass, and impaired cognition. ${ }^{8-11}$ Limited evidence also suggests a relationship between ADT and thromboembolic complications such as deep venous thrombosis (DVT), pulmonary embolism (PE), and arterial embolism (AE). ${ }^{12}$ Thromboembolic events (TEs), while treatable, are also potentially life-threatening. If men taking ADT for prostate cancer are at increased risk of thromboembolic disease, this risk must be considered when weighing the potential benefits and harms of treatments. Our objective was to estimate the impact of androgen deprivation on TEs in a population-based cohort of men with non-metastatic prostate cancer.

\section{METHODS}

\section{Data}

The primary data source was the Surveillance, Epidemiology, and End Results (SEER)Medicare database which links information from the National Cancer Institute (NCI)'s SEER cancer registry program with Medicare claims and enrollment records. The SEER program collects data from 17 population-based cancer registries in selected states and metropolitan areas covering $26 \%$ of the US population. Medicare is the primary health insurer for $97 \%$ of Americans 65 years and older, covering inpatient hospital care (Part A) and outpatient care and physician services (Part B). For all incident cancers, the SEER registries collect information regarding site and extent of disease, first course of cancerdirected therapy, and sociodemographic characteristics, with active follow-up for vital status and cause of death. ${ }^{13}$

Compared with the population of all US adults age 65 years and older, the SEER-Medicare population has a similar age and sex distribution but has more residents of urban and affluent areas and a smaller proportion of nonwhite individuals. ${ }^{13}$ The SEER-Medicare files were used in accordance with a data-use agreement from NCI, and the study was approved by the Institutional Review Board at Memorial Sloan-Kettering Cancer Center.

\section{Study Cohort}

We identified all cases of non-metastatic prostate cancer in the SEER-Medicare database diagnosed between 1999 and 2005. The cohort was restricted to patients 66 years or older and who had been enrolled in Parts A and B of Medicare for at least one year before diagnosis, because information from the year prior to diagnosis was necessary for estimating comorbidity. Patients diagnosed only at the time of death were excluded, as were patients 
who participated in a Medicare managed care plan at the time of diagnosis or any time thereafter. Men who had metastatic disease at the time of diagnosis were excluded, based on clinical extent-of-disease information in SEER.

\section{Treatment}

Medical and surgical ADT were identified by Current Procedural Terminology (CPT) codes for GnRH agonists and bilateral orchiectomy in Medicare claims at any time following diagnosis. Duration of ADT was categorized as less than 1 year, 1 to less than 3 years, and 3 or more years, based on the interval between first and last claim for GnRH agonist. Surgical ADT was included in the category of longest ADT duration ( $>3$ years). Other prostate cancer treatments identified in Medicare claims included surgery and radiation therapy (see codes in Appendix).

\section{Outcomes}

The primary endpoint was a TE, identified in Medicare claims by ICD-9 diagnosis codes for DVT, PE, or AE. When a patient had a single claim with multiple diagnosis codes indicating $\mathrm{PE}$ and one of DVT or AE, the event was classified as a PE. If a claim indicated both DVT and $\mathrm{AE}$ without $\mathrm{PE}$, the event was classified as an AE. For analysis of the cumulative number of events per patient, unique events were defined as those occurring at least 6 months apart.

\section{Covariates}

We examined several characteristics hypothesized to predict receipt of ADT or risk of TE and potentially confound the relationship between the two. Demographic characteristics from SEER included age at diagnosis, race, marital status, urban/rural location, and median income in the census tract of residence. Disease characteristics included clinical tumor stage, Gleason score, PSA, and lymph node involvement. Comorbidity was estimated using a modification of the Charlson comorbidity index based on inpatient, outpatient, and physician claims in the year before prostate cancer diagnosis. ${ }^{14,15}$ We also identified patients at elevated risk for TEs specifically based on the presence of a diagnosis code for stroke, ischemic heart disease, or a TE in the year prior to cancer diagnosis.

\section{Statistical Analysis}

Unadjusted associations between exposure to ADT and patient characteristics were examined using chi-square statistics. The impact of ADT on the risk of any TE was evaluated in a time-to-event framework, where the time origin was the date of prostate cancer diagnosis and patients who did not have an event were censored at the time of death or end of follow-up. Multivariable Cox proportional hazards regression was used to estimate the impact of ADT on TEs, controlling for demographic, disease, and health characteristics. In regression analysis, receipt of ADT and other treatments were analyzed as timedependent variables, with exposure to each treatment identified at the time of the first Medicare claim for that treatment. Hazard ratios (HR), 95\% confidence intervals (CI), and two-sided $P$-values were estimated for each covariate. We performed stratified analyses to assess whether the relationship between ADT exposure and the risk of a TE varied by age at diagnosis, disease stage and grade, and type of ADT. We also repeated the analysis separating venous TEs (PE and DVT) from arterial TEs (AE).

We examined the impact of duration of ADT on both time to first TE and total number of TEs. In both analyses duration of ADT was categorized as $<1$ year, $1-<3$ years or $3+$ years, based on the interval between first and last claim for ADT. In the time-to-event framework, ADT duration was treated as a time-dependent characteristic, varying for each patient based 
on his cumulative months of ADT exposure at each month, and the impact of ADT duration was estimated using multivariable Cox proportional hazards regression. The impact of ADT on the total number of TEs was estimated using multivariable negative binomial regression, stratified by total cumulative ADT exposure. All analyses were performed using SAS version 9.2 (SAS Institute Inc, Cary, NC). Results are reported in adherence with STROBE (Strengthening the Reporting of Observational Studies in Epidemiology) guidelines. ${ }^{16}$

\section{RESULTS \\ Cohort Characteristics}

The study cohort included 154,611 men diagnosed with non-metastatic prostate cancer between 1999 and 2005, of whom 58,466 (38\%) received ADT. In men who had ADT the median time from prostate cancer diagnosis to initiation of ADT was 1.3 months, and 83\% of those who received ADT initiated therapy within 6 months of diagnosis. Men who received ADT were older and more likely to live in non-metropolitan areas and areas with lower median income than men not receiving ADT (Table 1). They also had higher clinical stage and Gleason score, greater comorbidity and were more likely to have an elevated risk for a TE due to a diagnosis of stroke, ischemic heart disease, or TE in the year before cancer diagnosis. Men who had ADT were also more likely to have received radiation at some point following diagnosis. Only $2 \%$ of men who received any ADT underwent orchiectomy. Among the 57,009 men who had medical ADT, 56\% received ADT for $<1 \mathrm{yr}, 26 \%$ for 1 to $<3 \mathrm{yrs}$, and $19 \%$ for 3 yrs or more. The median number of Medicare claims for GnRH agonist therapy was 2,7 and 14 in each of these categories, respectively.

\section{Thromboembolic Events}

During a median follow-up of 52 months, 15,950 men (10.3\%) had at least one TE, including 8,829 (15\%) of those who had ADT and 7,121 (7\%) of those with no ADT (Table 2). In men with a TE, $30 \%$ had more than one event, and half of all TEs were DVTs. About one-fourth of all events were associated with an inpatient hospital stay. At 4 years after diagnosis, TE-free survival was $87 \%$ in men who had ADT and $94 \%$ in those who did not (log-rank $P<0.0001)$. Controlling for patient and tumor characteristics, comorbidity, and other cancer treatment, exposure to ADT increased the risk of a TE by more than $50 \%$ (adjusted HR $1.56,95 \%$ CI 1.50 to $1.61, P<0.0001$ ). The risk of a TE was also significantly increased among older men, black men, those who received surgery or radiation therapy, those with greater comorbidity, and men who had had a diagnosis of stroke, ischemic heart disease, or a TE in the year prior to cancer diagnosis (Table 3).

ADT had a similar impact on the risk of a TE in men younger than 75 years at diagnosis (adjusted HR 1.54, 95\% CI 1.46 to 1.62) and in men 75 and older (adjusted HR 1.59, 95\% CI 1.51 to 1.67). Results were also similar when the cohort was stratified by prognosis. Controlling for other factors associated with ADT increased the risk of a TE by 55\% (95\% CI 1.49 to 1.60) in men with a low risk of disease progression (clinical stage $\leq T 2$ and Gleason score 5 ) and by $83 \%$ (95\% CI 1.71 to 1.96) in men with a higher risk of disease progression (stage $>\mathrm{T} 2$ or Gleason score $>6$ ).

Patients who had surgical rather than medical ADT should have the highest risk for TEs, because these patients are exposed to constant castrate levels of androgen. Consistent with this hypothesis, we found that the impact of ADT on the risk of a TE was greater in men who had orchiectomy (adjusted HR compared with no ADT 1.97, 95\% CI 1.72 to 2.26) than in men who had androgen suppression by GnRH agonist (adjusted HR compared with no ADT $1.54,95 \%$ CI 1.49 to 1.60 ). ADT exposure was associated with both venous and arterial thromboembolic events, although the magnitude of the relationship was somewhat 
attenuated when these endpoints were analyzed separately. Controlling for other factors, ADT increased the risk of a DVT or PE by $27 \%$ (95\% CI 1.21 to 1.32) while it increased the risk of an $\mathrm{AE}$ by $18 \%$ (95\% CI 1.10 to 1.32 ).

Duration of ADT exposure was associated with both the risk of a first TE and the total number of TEs (Figure 1). Cumulative ADT exposure of $<1$ year increased the risk of TE by $40 \%$ (95\% CI 1.33 to 1.45 ), $1-<3$ years of ADT increased the risk by $66 \%$ (95\% CI 1.57 to 1.75 ), and 3 or more years of ADT doubled the risk (95\% CI 1.90 to 2.19), compared with no ADT, controlling for patient and disease characteristics, comorbidity and other cancer treatment (Figure 1, Panel A). The incidence rate ratio (IRR) for the impact of ADT on total number of TEs varied from 2.05 (95\% CI 1.89 to 2.23) in men exposed to less than 1 year of ADT to 2.94 (95\% CI 2.61 to 3.32) in those with more than 3 years of ADT or bilateral orchiectomy (Figure 1, Panel B).

\section{DISCUSSION}

In this large, population-based study of men diagnosed with non-metastatic prostate cancer, we found that ADT was associated with the risk of TEs. Men exposed to ADT, defined as GnRH agonist therapy or bilateral orchiectomy, had a greater risk of any TE after controlling for demographic and disease characteristics and other cancer treatments. Moreover, the risk of any TE and the total number of TEs both increased with longer durations of ADT.

Our results reinforce the findings of several prior studies. In another population-based study using the Swedish National Prostate Cancer Registry, men with advanced prostate cancer had an increased risk of TEs compared to a matched group of men without prostate cancer. ${ }^{12}$ Among the men with prostate cancer, those receiving primary ADT had the highest risk of venous thrombosis.

The association of androgen deprivation with increased risk of TEs has also been investigated in other clinical settings. GnRH agonists have been associated with adverse metabolic effects, including increased fat mass and decreased insulin sensitivity. ${ }^{17-19} \mathrm{In}$ addition, androgen deprivation from GnRH agonist therapy or orchiectomy has been associated with an increased risk of developing diabetes. ${ }^{9,20}$ The impact of these adverse physiologic effects can alter serum lipoproteins and lead to obesity and increased arterial stiffness which may increase the risk of TEs. ${ }^{21}$ In preliminary experimental studies, the androgen receptor on megakaryocytic cells has been shown to regulate platelet activation and androgen has been shown to inhibit arterial thrombosis. ${ }^{23,24}$

In addition to ADT, both malignancy itself and host factors have been associated with increased risk of thromboembolic disease. ${ }^{25-29}$ TEs are also common complications after surgical intervention, affecting $0.5 \%$ to $40 \%$ of patients in the perioperative period. ${ }^{30}$ Although we could not observe disease recurrences in the SEER-Medicare dataset, we excluded patients with metastatic disease at diagnosis and we controlled for important tumor characteristics including clinical stage, histological grade, preoperative PSA, and lymph node status; patient characteristics such as age, general comorbidity, and specific conditions associated with thromboembolic disease; and other cancer treatments including surgery. Adjusting for all of these factors, ADT had an independent effect on the risk of thromboembolic complications, increasing the risk of any event as well as the total number of events. Death due to prostate cancer was observed in less than 5\% of patients who had a TE, suggesting that tumor progression is unlikely to confound the relationship between ADT and TE in this cohort. 
The benefit of ADT, and thus the benefit-risk tradeoff, varies by disease severity. Men with high-risk prostate cancer, defined by multifactorial risk prediction algorithms, have a significantly greater likelihood of biochemical relapse compared to those with more favorable disease characteristics. Several randomized clinical trials have demonstrated that ADT improves disease-specific survival in men with high-risk prostate cancer treated with radiation therapy. ${ }^{31-34}$ However, subgroup analyses suggest no statistically significant survival benefit in patients with low-risk disease. ${ }^{35} \mathrm{In}$ men with intermediate-risk prostate cancer, ADT improves prognosis, but survival differences appear to be mitigated by a patient's level of comorbidities. ${ }^{35}$ In patients treated with radical prostatectomy, neoadjuvant ADT may decrease the rate of positive surgical margins, but it has not been shown to improve disease-free or overall survival. ${ }^{36}$ Separate from its effect on survival, the impact of ADT on quality of life may be mixed. In a population-based sample of men with localized prostate cancer who received neither surgery nor radiation therapy, those treated with ADT reported greater satisfaction with their treatment decision, but greater physical discomfort than men who had no ADT. ${ }^{37}$

Even when the benefits of ADT are likely to outweigh the risks, the optimal duration of therapy is uncertain. One randomized trial found greater overall survival with 36 months of ADT compared to 6 months in men with high-risk prostate cancer patients treated with radiation therapy. ${ }^{38}$ However, a pooled analysis of patients enrolled in three randomized trials and treated with long-term or short-term ADT and radiation therapy concluded that a longer duration of ADT was not associated with improved survival. ${ }^{39}$ Moreover, in a randomized trial of radiation therapy with or without ADT, patients who received long-term ADT had a higher rate of non-cancer deaths than patients on short-term ADT. ${ }^{40}$

While our findings are relevant to clinical decision-making for individual patients, they also have important implications for public health and the economic burden of prostate cancer. Although prostate cancer accounts for a substantial fraction of new cancer cases and deaths each year, most men at are diagnosed at an early stage with a favorable prognosis. More than $45 \%$ of patients will die of causes other than prostate cancer and TEs are the second most common cause of death among all cancer patients. ${ }^{41,42}$ In 1999, ADT was given to half of all prostate cancer patients and accounted for one third of Medicare expenditures for prostate cancer treatment. ${ }^{3}$ However, use of ADT appears sensitive to the level of reimbursement for physicians. Two studies showed a substantial decline in utilization after Medicare payments for ADT administration were reduced. ${ }^{43,44}$

Several limitations of our analysis should be noted. In this observational study, our findings demonstrate an association between ADT and TEs, but we are limited in our ability to infer causality. Although we were able to control for numerous potential confounders, we could not control for smoking history or body mass index, two factors associated with thromboembolic complications. We also had no information regarding patient preferences or physician recommendations for treatment, or other factors which may be associated with both receipt of ADT and with the underlying risk of TE. During the years of our study, we could not identify another potential confounder, oral anticoagulant therapy, in Medicare claims. Finally, our results may not be generalizable to prostate cancer patients younger than 66 years.

Our results add to an expanding body of literature which suggests that concerns regarding ADT are warranted, and they emphasize the importance of identifying those men at highest risk for complications and implementing strategies to prevent treatment-related morbidity. The implications of these findings prompt several recommendations for prostate cancer patients and their physicians. First, men considering ADT should be assessed for TE risk factors, such as obesity, smoking, prolonged immobility, and personal history of stroke or 
TEs, before starting therapy. Second, for men who initiate ADT, they and their physicians need to be aware of and vigilant for thromboembolic complications. Most importantly, the treatment decision-making process should include a careful discussion, tailored to the individual patient based on his health and the characteristics of his disease, of the expected benefits and potential harms of ADT and other treatment options.

\section{Supplementary Material}

Refer to Web version on PubMed Central for supplementary material.

\section{Acknowledgments}

The authors acknowledge the efforts of the Applied Research Program, NCI; the Office of Research, Development and Information, CMS; Information Management Services (IMS), Inc.; and the Surveillance, Epidemiology, and End Results (SEER) Program tumor registries in the creation of the SEER-Medicare database.

Funding: This study was supported by the Sidney Kimmel Center for Prostate and Urologic Cancers. Supported in part by funds from David H. Koch through the Prostate Cancer Foundation and by a grant from the National Cancer Institute (RC1CA146516, PI: Eastham). Dr. Elkin is supported by a Career Development Award from the National Cancer Institute (1K07CA118189).

\section{REFERENCES}

1. Jemal A, Siegel R, Xu J, Ward E. Cancer Statistics, 2010. CA Cancer J Clin. Jul 7; 2010 60(5):277_ 300. [PubMed: 20610543]

2. Han M, Partin AW, Zahurak M, Piantadosi S, Epstein JI, Walsh PC. Biochemical (prostate specific antigen) recurrence probability following radical prostatectomy for clinically localized prostate cancer. J Urol. Feb; 2003 169(2):517-523. [PubMed: 12544300]

3. Shahinian VB, Kuo YF, Freeman JL, Orihuela E, Goodwin JS. Increasing use of gonadotropinreleasing hormone agonists for the treatment of localized prostate carcinoma. Cancer. Apr 15; 2005 103(8):1615-1624. [PubMed: 15742331]

4. Cooperberg MR, Grossfeld GD, Lubeck DP, Carroll PR. National practice patterns and time trends in androgen ablation for localized prostate cancer. J Natl Cancer Inst. Jul 2; 2003 95(13):981-989. [PubMed: 12837834]

5. Huggins C, Hodges CV. Studies on prostatic cancer. I. The effect of castration, of estrogen and androgen injection on serum phosphatases in metastatic carcinoma of the prostate. CA Cancer $\mathrm{J}$ Clin. Jul-Aug;1972 22(4):232-240. [PubMed: 4625049]

6. Baba K, Yajima M, Carrier S, et al. Effect of testosterone on the number of NADPH diaphorasestained nerve fibers in the rat corpus cavernosum and dorsal nerve. Urology. Sep 1; 2000 56(3): 533-538. [PubMed: 10962339]

7. Karling P, Hammar M, Varenhorst E. Prevalence and duration of hot flushes after surgical or medical castration in men with prostatic carcinoma. J Urol. Oct; 1994 152(4):1170-1173. [PubMed: 8072086]

8. Saigal CS, Gore JL, Krupski TL, Hanley J, Schonlau M, Litwin MS. Androgen deprivation therapy increases cardiovascular morbidity in men with prostate cancer. Cancer. Oct 1; 2007 110(7):14931500. [PubMed: 17657815]

9. Keating NL, O’Malley AJ, Smith MR. Diabetes and cardiovascular disease during androgen deprivation therapy for prostate cancer. J Clin Oncol. Sep 20; 2006 24(27):4448-4456. [PubMed: 16983113]

10. Nelson CJ, Lee JS, Gamboa MC, Roth AJ. Cognitive effects of hormone therapy in men with prostate cancer: a review. Cancer. Sep 1; 2008 113(5):1097-1106. [PubMed: 18666210]

11. D'Amico AV, Denham JW, Crook J, et al. Influence of androgen suppression therapy for prostate cancer on the frequency and timing of fatal myocardial infarctions. J Clin Oncol. Jun 10; 2007 25(17):2420-2425. [PubMed: 17557956] 
12. Van Hemelrijck M, Adolfsson J, Garmo H, et al. Risk of thromboembolic diseases in men with prostate cancer: results from the population-based PCBaSe Sweden. Lancet Oncol. May; 2010 11(5):450-458. [PubMed: 20395174]

13. Warren JL, Klabunde CN, Schrag D, Bach PB, Riley GF. Overview of the SEER-Medicare data: content, research applications, and generalizability to the United States elderly population. Med Care. Aug; 2002 40(8 Suppl):IV-3-18.

14. Romano PS, Roos LL, Jollis JG. Adapting a clinical comorbidity index for use with ICD-9-CM administrative data: differing perspectives. J Clin Epidemiol. Oct; 1993 46(10):1075-1079. discussion 1081-1090. [PubMed: 8410092]

15. Klabunde CN, Potosky AL, Legler JM, Warren JL. Development of a comorbidity index using physician claims data. J Clin Epidemiol. Dec; 2000 53(12):1258-1267. [PubMed: 11146273]

16. von Elm E, Altman DG, Egger M, Pocock SJ, Gotzsche PC, Vandenbroucke JP. The Strengthening the Reporting of Observational Studies in Epidemiology (STROBE) statement: guidelines for reporting observational studies. Lancet. Oct 20; 2007 370(9596):1453-1457. [PubMed: 18064739]

17. Smith MR, Finkelstein JS, McGovern FJ, et al. Changes in body composition during androgen deprivation therapy for prostate cancer. J Clin Endocrinol Metab. Feb; 2002 87(2):599-603. [PubMed: 11836291]

18. Smith MR, Lee H, Nathan DM. Insulin sensitivity during combined androgen blockade for prostate cancer. J Clin Endocrinol Metab. Apr; 2006 91(4):1305-1308. [PubMed: 16434464]

19. Berruti A, Dogliotti L, Terrone C, et al. Changes in bone mineral density, lean body mass and fat content as measured by dual energy $\mathrm{x}$-ray absorptiometry in patients with prostate cancer without apparent bone metastases given androgen deprivation therapy. J Urol. Jun; 2002 167(6):23612367. discussion 2367. [PubMed: 11992038]

20. Keating NL, O’Malley AJ, Freedland SJ, Smith MR. Diabetes and cardiovascular disease during androgen deprivation therapy: observational study of veterans with prostate cancer. J Natl Cancer Inst. Jan 6; 2010 102(1):39-46. [PubMed: 19996060]

21. Smith JC, Bennett S, Evans LM, et al. The effects of induced hypogonadism on arterial stiffness, body composition, and metabolic parameters in males with prostate cancer. J Clin Endocrinol Metab. Sep; 2001 86(9):4261-4267. [PubMed: 11549659]

22. Ferenchick GS, Hirokawa S, Mammen EF, Schwartz KA. Anabolic-androgenic steroid abuse in weight lifters: evidence for activation of the hemostatic system. Am J Hematol. Aug; 1995 49(4): 282-288. [PubMed: 7639272]

23. Li S, Li X, Li J, Deng X, Li Y, Cong Y. Experimental arterial thrombosis regulated by androgen and its receptor via modulation of platelet activation. Thromb Res. 2007; 121(1):127-134. [PubMed: 17451792]

24. Khetawat G, Faraday N, Nealen ML, et al. Human megakaryocytes and platelets contain the estrogen receptor beta and androgen receptor (AR): testosterone regulates AR expression. Blood. Apr 1; 2000 95(7):2289-2296. [PubMed: 10733498]

25. Lippi G, Plebani M, Franchini M, Guidi GC, Favaloro EJ. Prostate-specific antigen, prostate cancer, and disorders of hemostasis. Semin Thromb Hemost. Oct; 2009 35(7):654-664. [PubMed: 20013532]

26. Wahrenbrock M, Borsig L, Le D, Varki N, Varki A. Selectin-mucin interactions as a probable molecular explanation for the association of Trousseau syndrome with mucinous adenocarcinomas. J Clin Invest. Sep; 2003 112(6):853-862. [PubMed: 12975470]

27. Rickles FR, Falanga A. Molecular basis for the relationship between thrombosis and cancer. Thromb Res. Jun 15; 2001 102(6):V215-224. [PubMed: 11516455]

28. Khorana AA, Francis CW, Culakova E, Kuderer NM, Lyman GH. Frequency, risk factors, and trends for venous thromboembolism among hospitalized cancer patients. Cancer. Nov 15; 2007 110(10):2339-2346. [PubMed: 17918266]

29. Heit JA, Silverstein MD, Mohr DN, Petterson TM, O'Fallon WM, Melton LJ 3rd. Risk factors for deep vein thrombosis and pulmonary embolism: a population-based case-control study. Arch Intern Med. Mar 27; 2000 160(6):809-815. [PubMed: 10737280] 
30. Klevecka V, Burmester L, Musch M, Roggenbuck U, Kroepfl D. Intraoperative and early postoperative complications of radical retropubic prostatectomy. Urol Int. 2007; 79(3):217-225. [PubMed: 17940353]

31. Roach M 3rd, Bae K, Speight J, et al. Short-term neoadjuvant androgen deprivation therapy and external-beam radiotherapy for locally advanced prostate cancer: long-term results of RTOG 8610. J Clin Oncol. Feb 1; 2008 26(4):585-591. [PubMed: 18172188]

32. D'Amico AV, Chen MH, Renshaw AA, Loffredo M, Kantoff PW. Androgen suppression and radiation vs radiation alone for prostate cancer: a randomized trial. JAMA. Jan 23; 2008 299(3): 289-295. [PubMed: 18212313]

33. D’Amico AV, Manola J, Loffredo M, Renshaw AA, DellaCroce A, Kantoff PW. 6-month androgen suppression plus radiation therapy vs radiation therapy alone for patients with clinically localized prostate cancer: a randomized controlled trial. JAMA. Aug 18; 2004 292(7):821-827. [PubMed: 15315996]

34. Denham JW, Steigler A, Lamb DS, et al. Short-term androgen deprivation and radiotherapy for locally advanced prostate cancer: results from the Trans-Tasman Radiation Oncology Group 96.01 randomised controlled trial. Lancet Oncol. Nov; 2005 6(11):841-850. [PubMed: 16257791]

35. Nguyen PL, Chen MH, Beard CJ, et al. Radiation with or without 6 months of androgen suppression therapy in intermediate- and high-risk clinically localized prostate cancer: a postrandomization analysis by risk group. Int J Radiat Oncol Biol Phys. Jul 15; 2010 77(4):10461052. [PubMed: 19864082]

36. Klotz LH, Goldenberg SL, Jewett MA, et al. Long-term followup of a randomized trial of 0 versus 3 months of neoadjuvant androgen ablation before radical prostatectomy. J Urol. Sep; 2003 170(3):791-794. [PubMed: 12913699]

37. Potosky AL, Reeve BB, Clegg LX, et al. Quality of life following localized prostate cancer treated initially with androgen deprivation therapy or no therapy. J Natl Cancer Inst. Mar 20; 2002 94(6): 430-437. [PubMed: 11904315]

38. Bolla M, de Reijke TM, Van Tienhoven G, et al. Duration of androgen suppression in the treatment of prostate cancer. N Engl J Med. Jun 11; 2009 360(24):2516-2527. [PubMed: 19516032]

39. D'Amico AV, Denham JW, Bolla M, et al. Short- vs long-term androgen suppression plus external beam radiation therapy and survival in men of advanced age with node-negative high-risk adenocarcinoma of the prostate. Cancer. May 15; 2007 109(10):2004-2010. [PubMed: 17397033]

40. Hanks GE, Pajak TF, Porter A, et al. Phase III trial of long-term adjuvant androgen deprivation after neoadjuvant hormonal cytoreduction and radiotherapy in locally advanced carcinoma of the prostate: the Radiation Therapy Oncology Group Protocol 92-02. J Clin Oncol. Nov 1; 2003 21(21):3972-3978. [PubMed: 14581419]

41. Levitan N, Dowlati A, Remick SC, et al. Rates of initial and recurrent thromboembolic disease among patients with malignancy versus those without malignancy. Risk analysis using Medicare claims data. Medicine (Baltimore). Sep; 1999 78(5):285-291. [PubMed: 10499070]

42. Brown BW, Brauner C, Minnotte MC. Noncancer deaths in white adult cancer patients. J Natl Cancer Inst. Jun 16; 1993 85(12):979-987. [PubMed: 8496983]

43. Shahinian VB, Kuo YF, Gilbert SM. Reimbursement policy and androgen-deprivation therapy for prostate cancer. N Engl J Med. Nov 4; 2010 363(19):1822-1832. [PubMed: 21047226]

44. Weight CJ, Klein EA, Jones JS. Androgen deprivation falls as orchiectomy rates rise after changes in reimbursement in the U.S. Medicare population. Cancer. May 15; 2008 112(10):2195-2201. [PubMed: 18393326] 


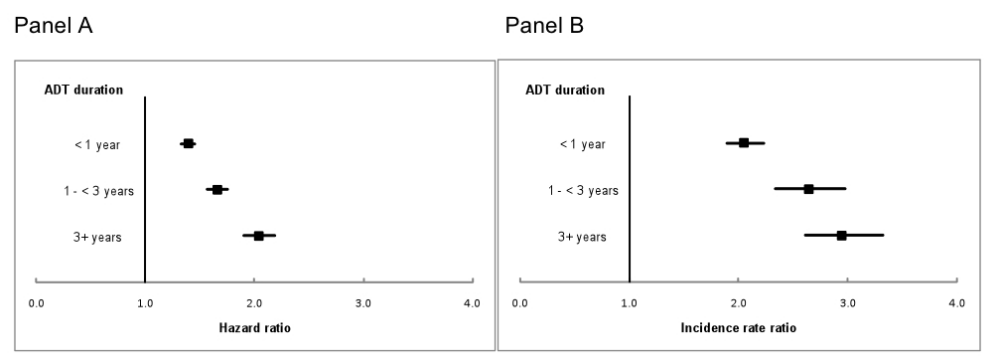

\section{Figure 1.}

Adjusted impact of ADT duration on thromboembolic events Panel A shows the adjusted impact of ADT duration on risk of first TE with ADT duration analyzed as a time-dependent characteristic, varying for each patient based on his cumulative months of ADT exposure at each month. Men who had surgical ADT were assumed to have continuous ADT exposure from the time of orchiectomy. Each category of ADT duration was compared with no ADT.

Panel B shows the adjusted impact of ADT on total number of TEs, estimated with negative binominal regression, stratified by total cumulative ADT exposure. Men who had surgical ADT were included in the group with 3 or more years of ADT exposure. Each category of ADT duration was compared with no ADT. All incidence rate ratios were statistically significant at ADT: androgen deprivation therapy

TE: thromboembolic event 
Table 1

Characteristics of cohort by receipt of androgen deprivation therapy

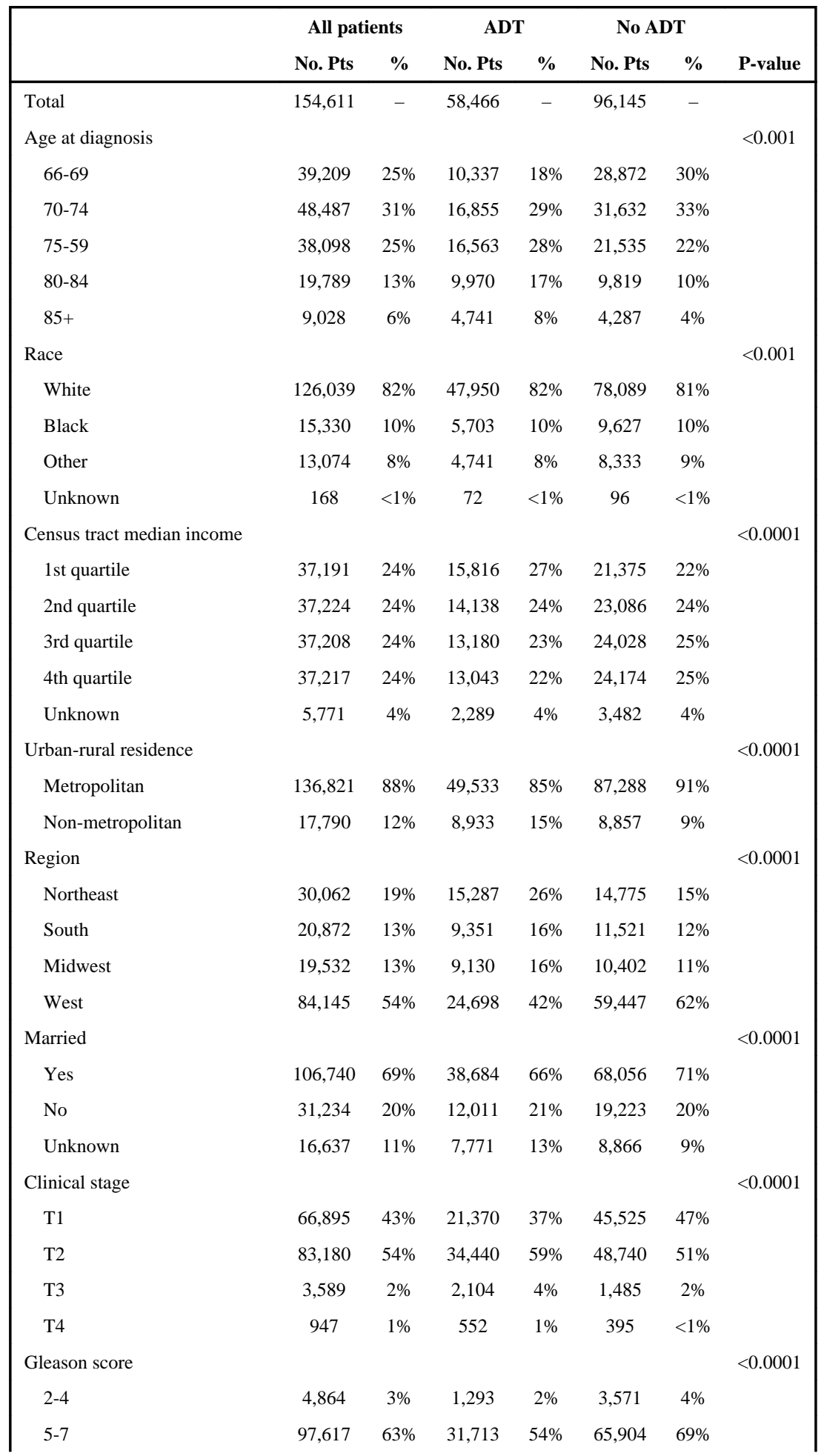




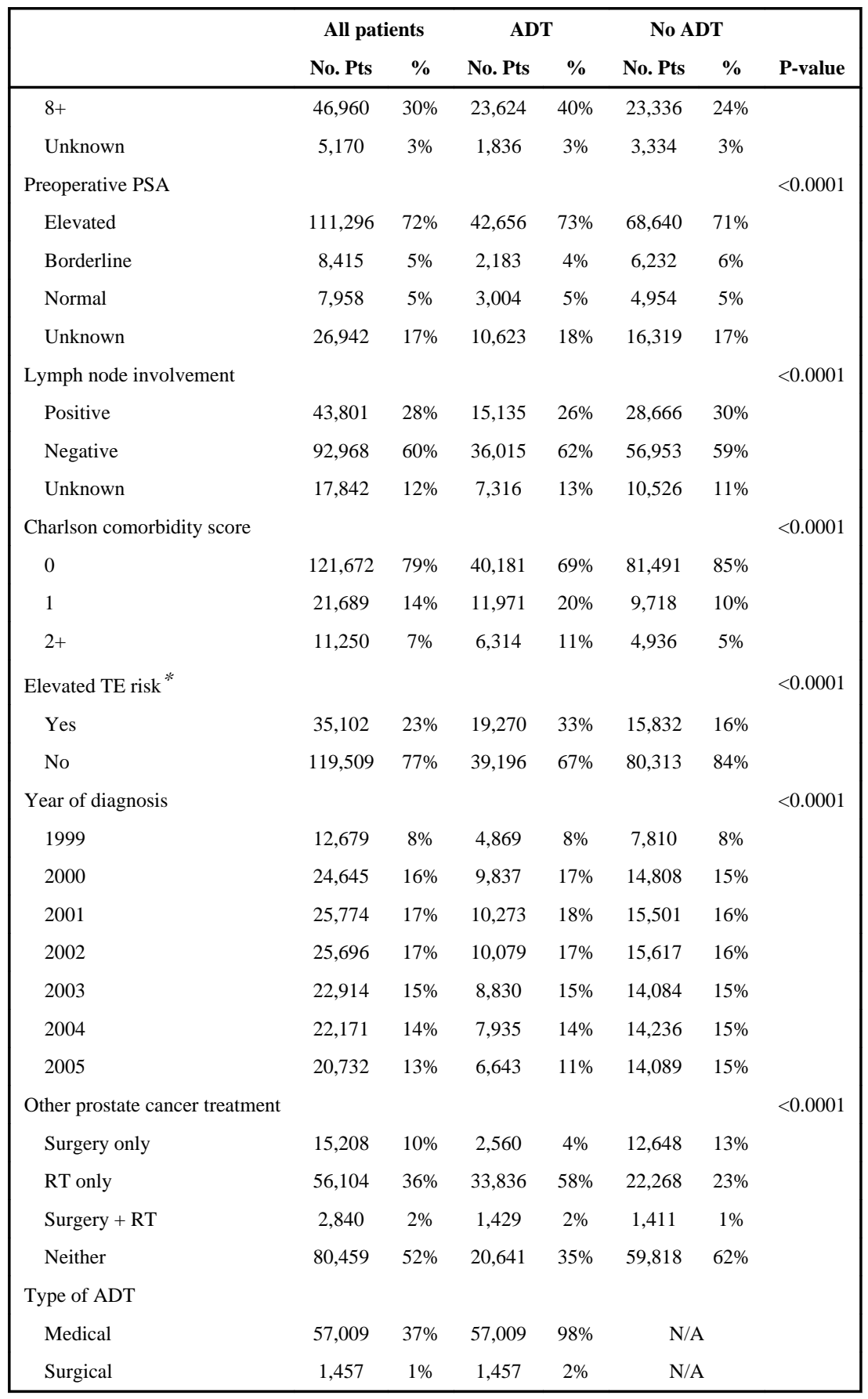

ADT: Androgen deprivation therapy

TE: Thromboembolic event

PSA: prostate-specific antigen

RT: Radiation therapy

Stroke, ischemic heart disease, or TE in year prior to prostate cancer diagnosis 
Table 2

Frequency of thromboembolic events by ADT exposure ADT No ADT

\begin{tabular}{|c|c|c|c|c|c|c|}
\hline & \multicolumn{3}{|c|}{$\begin{array}{c}\text { ADT } \\
(N=58,466)\end{array}$} & \multicolumn{3}{|c|}{$\begin{array}{c}\text { No ADT } \\
(N=96,145)\end{array}$} \\
\hline & $\begin{array}{l}\text { No. } \\
\text { Pts }\end{array}$ & $\begin{array}{l}\% \text { of } \\
\text { Pts }\end{array}$ & No. Events & $\begin{array}{l}\text { No. } \\
\text { Pts }\end{array}$ & $\begin{array}{l}\% \text { of } \\
\text { Pts }\end{array}$ & No. Events \\
\hline \multicolumn{7}{|l|}{ Thromboembolic events } \\
\hline Any event & 8,829 & $15 \%$ & 13,330 & 7,121 & $7 \%$ & 10,318 \\
\hline Deep venous thrombosis & 4,360 & $7 \%$ & 6,623 & 3,564 & $4 \%$ & 5,191 \\
\hline Arterial embolism & 2,574 & $4 \%$ & 3,834 & 2,011 & $2 \%$ & 2,874 \\
\hline Pulmonary embolism & 1,895 & $3 \%$ & 2,873 & 1,546 & $2 \%$ & 2,253 \\
\hline
\end{tabular}


Table 3

Predictors of time to first thromboembolic event

\begin{tabular}{|c|c|c|}
\hline Characteristic & Adjusted HR (95\% CI) & P-value \\
\hline \multicolumn{3}{|l|}{ Androgen deprivation ${ }^{*}$} \\
\hline No & Reference & \\
\hline Yes & $1.54(1.48-1.59)$ & $<0.0001$ \\
\hline \multicolumn{3}{|l|}{ Prostate cancer surgery ${ }^{*}$} \\
\hline No & Reference & \\
\hline Yes & $1.53(1.45-1.62)$ & $<0.0001$ \\
\hline \multicolumn{3}{|l|}{ Radiation therapy $^{*}$} \\
\hline No & Reference & \\
\hline Yes & $1.34(1.29-1.39)$ & $<0.0001$ \\
\hline \multicolumn{3}{|l|}{ Age at diagnosis } \\
\hline $66-69$ & Reference & \\
\hline $70-74$ & $1.13(1.08-1.18)$ & $<0.0001$ \\
\hline $75-59$ & $1.30(1.24-1.36)$ & \\
\hline $80-84$ & $1.54(1.45-1.62)$ & \\
\hline $85+$ & $1.62(1.50-1.75)$ & \\
\hline \multicolumn{3}{|l|}{ Race } \\
\hline White & Reference & \\
\hline Black & $1.32(1.26-1.39)$ & $<0.0001$ \\
\hline Other/Unknown & $0.73(0.68-0.79)$ & \\
\hline \multicolumn{3}{|c|}{ Census tract median income } \\
\hline 1st quartile & Reference & \\
\hline 2nd quartile & $0.93(0.89-0.97)$ & $<0.0001$ \\
\hline 3rd quartile & $0.89(0.85-0.94)$ & \\
\hline 4th quartile & $0.89(0.84-0.93)$ & \\
\hline Unknown & $1.09(1.00-1.18)$ & \\
\hline \multicolumn{3}{|l|}{ Urban-rural residence } \\
\hline Metropolitan & Reference & \\
\hline Non-Metropolitan & $0.88(0.84-0.93)$ & $<0.0001$ \\
\hline \multicolumn{3}{|l|}{ Geographic area } \\
\hline Northeast & Reference & \\
\hline South & $0.89(0.84-0.94)$ & $<0.0001$ \\
\hline Midwest & $1.14(1.09-1.20)$ & \\
\hline West & $0.80(0.77-0.83)$ & \\
\hline \multicolumn{3}{|l|}{ Married } \\
\hline No/Unknown & Reference & \\
\hline Yes & $0.93(0.90-0.96)$ & $<0.0001$ \\
\hline \multicolumn{3}{|l|}{ Gleason score } \\
\hline $2-7$ & Reference & $<0.001$ \\
\hline $8-10$ & $1.02(0.98-1.06)$ & \\
\hline
\end{tabular}




\begin{tabular}{|c|c|c|}
\hline Characteristic & Adjusted HR (95\% CI) & P-value \\
\hline Unknown & $1.19(1.10-1.29)$ & \\
\hline \multicolumn{3}{|l|}{ Clinical stage } \\
\hline $\mathrm{T} 1$ & Reference & \\
\hline $\mathrm{T} 2$ & $0.98(0.95-1.01)$ & $<0.0001$ \\
\hline $\mathrm{T} 3 / \mathrm{T} 4$ & $1.20(1.10-1.30)$ & \\
\hline \multicolumn{3}{|c|}{ Lymph node involvement } \\
\hline Negative & Reference & \\
\hline Positive & $1.04(0.98-1.11)$ & NS \\
\hline Unknown & $0.99(0.95-1.04)$ & \\
\hline \multicolumn{3}{|l|}{ Preoperative PSA } \\
\hline Normal & Reference & \\
\hline Borderline & $1.03(0.94-1.14)$ & $<0.0001$ \\
\hline Elevated & $0.99(0.92-1.06)$ & \\
\hline Unknown & $1.17(1.07-1.25)$ & \\
\hline \multicolumn{3}{|l|}{ Elevated TE risk } \\
\hline No & Reference & \\
\hline Yes & $1.76(1.69-1.82)$ & $<0.0001$ \\
\hline \multicolumn{3}{|c|}{ Charlson comorbidity score } \\
\hline 0 & Reference & \\
\hline 1 & $1.52(1.46-1.58)$ & $<0.0001$ \\
\hline $2+$ & $2.16(2.06-2.27)$ & \\
\hline Year of diagnosis & $1.02(1.00-1.03)$ & $<.02$ \\
\hline
\end{tabular}

HR: Hazard ratio

TE: Thromboembolic event

PSA: prostate-specific antigen

P-value for adjusted association between characteristic and hazard of first TE

* All prostate cancer treatments analyzed as time-dependent characteristics 